\title{
Inattention, Passivity and Reading Ability in Attention-Deficit Hyperactivity Disorder in a Greek Community Sample
}

Helen Lazaratou ${ }^{1 *}$, Maria Vlassopoulos ${ }^{1}$, Zacharias Kalogerakis ${ }^{1}$, George Zelios ${ }^{1}$, Dimitris Anagnostopoulos ${ }^{1}$ and Georges Dellatolas $^{2}$

${ }^{1}$ Child and Adolescent Psychiatric Unit, Community Mental Health Center, 1st Psychiatric Department, Medical School, University of Athens, Greece ${ }^{2}$ Inserm and Laboratory of Psychology and Cognitive Neuroscience, CNRS UMR8189, Université Paris Descartes, France

\begin{abstract}
Background: Studies on Attention-Deficit Hyperactivity Disorder (ADHD) show high comorbidity with learning disorders. This study examines the relationships between inattention, hyperactivity and reading performance in a nonreferred sample of second grade schoolchildren in an Athenian borough.

Methods: 201 pupils attending second grade in public schools were assessed for reading ability. The reading test was appropriate for second grade pupils according to the Greek curriculum. Teachers completed the Connors Rating Scale (CTRS) and the Achenbach's Teacher's Report Form (TRF).

Results: Attention/learning difficulties reported by the teacher were negatively associated with reading skills, but hyperactivity and other behaviour problems were not. Furthermore, in linear regression partialling out attention/ learning difficulties, teachers' reports of hyperactivity or externalizing difficulties was positively associated with reading skills. Girls showed better reading skills and less hyperactivity than boys. Moreover, passivity was found to be a compounding factor in reading difficulties.
\end{abstract}

Conclusion: Among the three subtypes of ADHD according to DSM-IV, the predominantly inattentive has more possibilities to contribute to reading difficulties, and even more so if it is combined with a child's passivity.

Keywords: Attention-deficit hyperactivity disorder; Inattention; Reading ability

\section{Introduction}

Attention-Deficit Hyperactivity Disorder (ADHD) is a highly prevalent and complex neurodevelopmental condition characterized by persistent inattention and/or hyperactivity-impulsivity. Numerous genetic, neurochemical, neuroimaging and neuropsychological studies suggest that $\mathrm{ADHD}$ is related to deficits in key brain regions subserving attention and executive functions [1]. ADHD has a genetic and biochemical basis, but environmental factors, prenatal, perinatal, and postnatal in origin, might also be implicated in its etiology [2-5].

Children in community samples, who show symptoms of inattention, hyperactivity and impulsivity, with or without formal diagnosis of ADHD, show also poor academic and educational outcomes [6]. In particular, a strong association of Reading Difficulties (RD) with ADHD has been repeatedly reported [7,8]. A genetic aetiology, which is partly shared, may be responsible for this comorbidity, as supported by behavioural and genetic studies, in both clinical and community samples [9-13]. Environmental factors were also reported to contribute to the link between RD and inattention [14]. It is suggested by Roy and Rutter [15], that reading performance may also be associated with institutional upbringing. Consequently, the environmental influence of being raised 'in care' might have an impact on reading performance either directly or indirectly owing to the increased levels of inattention which accompany institutional upbringing.

Other studies suggest common cognitive components in RD and ADHD, such as deficits in language impairment [16], processing speed [17], phonological processing [18], or time perception and psychoacoustic tasks $[19,20]$.

There are some differences concerning gender and reading difficulties or ADHD. Girls showed better reading skills than boys. In fact the epidemiology of ADHD and RD show higher percentages of boys referred for mental health services than girls [21-23]. This is further corroborated by the finding that men and women differ in areas of the brain that are activated during phonologic processing, which may lead to girls being better able to compensate for a reading deficit compared to boys [24]. However, other studies [25,26] maintain that the clinical correlates of ADHD are not influenced by gender. According to them, gender differences reported in subjects from clinical settings may be due to referral biases.

A commonly used rating scale to screen for ADHD and monitor treatment in children is the Conners Rating Scale [27-29]. The Conners is specifically linked to the DSM-IV criteria for ADHD, oppositional defiant disorder, and conduct disorder. Another commonly used scale is the Achenbach Child Behavior Checklist (CBCL), Parent and Teacher Report Form (TRF), designed to stratify "externalising behaviors" such as hyperactivity and aggression, and "internalising behaviors" related to anxiety and mood concerns [30,31].

Factor analytic studies of parent and teacher symptom ratings have fairly consistently identified two broad distinguishable behavioural dimensions that best characterize ADHD: inattention and hyperactivityimpulsivity.

Data from two longitudinal studies in Australia and New Zealand, where separate measures of inattention and hyperactivity were considered, showed that earlier levels of inattention, but not overactive behaviors, significantly predicted later levels of school difficulties [32]. This stronger association of learning difficulties with inattention than

*Corresponding author: Helen Lazaratou, Assoc. Professor in Child Psychiatry Child and Adolescent Psychiatric Unit, Community Mental Health Center, 1st Psychiatric Department, Medical School, University of Athens, 14 Delou Street Kessariani, 16121, Athens, Greece, Tel: 0030-210-7640111/0030-210-7644705 Fax: 0030-210-7662829; E-mail: elazar@med.uoa.gr

Received October 29, 2013; Accepted December 30, 2013; Published January 02, 2014

Citation: Lazaratou H, Vlassopoulos M, Kalogerakis Z, Zelios G (2014) Inattention Passivity and Reading Ability in Attention-Deficit Hyperactivity Disorder in a Greek Community Sample. J Psychol Abnorm Child 3: 109. doi:10.4172/23299525.1000109

Copyright: (c) 2014 Lazaratou $\mathrm{H}$, et al. This is an open-access article distributed under the terms of the Creative Commons Attribution License, which permits unrestricted use, distribution, and reproduction in any medium, provided the original author and source are credited. 
with hyperactivity has been repeatedly reported [33-35] and recent studies confirm that inattentive behaviours are associated with $\mathrm{RD}$, in particular to reading fluency and comprehension [36-38]. The impact of inattention may have repercussions from school entry and appears to be a predictor of later reading ability $[39,40]$.

The aim of the present study is to study the relationships between tested reading ability and hyperactivity, inattention, in a non-referred sample of second grade public school children in Greece. Specifically, given the stronger phenotypic and genetic association of reading with inattentive rather than hyperactive-impulsive symptoms, we hypothesized that the relationship with reading difficulties in our non-referred sample would be stronger for inattentiveness than for hyperactivity-impulsivity.

\section{Methods}

\section{Design}

This study was conducted by a Community Mental Health Centre (CMHC) in Athens, Greece. The sample was elicited through stratified sampling: (i) all of the schools in the CMCH's catchment participated; (ii) $100 \%$ of the schools' pupils who were attending second grade during the period from $01 / 09 / 2006$ to $15 / 06 / 2007$, and who were aged between 7 years to 8 years (84 to 96 months), were potential participants; (iii) a random selection of $55 \%$ of the above pupils participated in the study. There was a $6 \%$ parental refusal rate. Consequently the sample thus consisted of 201 children, 92 boys (45.8\%) and 109 girls (54.2\%).

\section{Study instruments}

(a) Teacher's Report Form (TRF): This is as teacher-rated behavioural inventory with a 3-point scale, yielding the same T-scores as the parents' CBCL [31]. It has been translated into Greek and standardized on the Greek population [41]. For the purposes of this study, only the Internalizing and Externalizing scales are analysed.

(b) Conners-28 item questionnaire: This questionnaire assesses behavioural difficulties which are rated by the teacher on a 4-point scale, "not at all", "just a little", "pretty much", and "very much present", coded $0,1,2$ and 3 respectively. It is designed for ADHD screening of children aged from 4 to 17 years [27-28]. The instrument has been standardized on the Greek population [42]. In the present study, a detailed analysis of the relationship between the Conner's items and reading skills is proposed.

(c) Reading ability test: This test is comprised of a text based on the Aesopian myth of "The Wise Frog" which is relevant to the skills, taught knowledge and interests of 7-8 years old Greek children. The test has the following characteristics: (i) it is comprised of 95 words (letters' size 16) similar to the letters of the Language Official Handbook (Year 1, Year 2), accompanied by a pleasant illustration; (ii) the text level corresponds to that of the Official Handbook of Greek Elementary School, Grade 1 and 2 [43]. The test was administrated at the schools by six teachers, who were specifically trained for the task. Their assessments were evaluated during a pilot study and no statistically significant "teacher" effect was found [44]. Reading ability was scored for: (i) Time (in seconds), from the initial uttered syllable until the reading task was completed; (ii) Accuracy: number of errors (stress errors, deletions, substitutions, additions, reversals, reiterations of letters, syllables and words, punctuation deletions and skipping rows of text); (iii) Comprehension: 8 specific questions on text comprehension were administered orally and the number of correct answers was noted. Some examples of comprehension questions were: 'Where did the frogs live?' and 'Why did the frogs have to leave the lake?' The test was administered individually. The test's duration was approximately 10 minutes.

\section{Procedure}

All members of the research team and all teachers involved participated in a meeting before testing commenced. The aim of the meeting was to exchange information about the study's objectives and the specific procedures to be used. Teachers were given the Conners-28 questionnaire and the Teachers' Report Form, which they were requested to complete for all the pupils in their class.

\section{Statistical analysis}

Statistical analysis focused on the relations between the Conners-28 teacher questionnaire and reading scores. On the item level, correlations with reading scores using Spearman's rho were examined, and linear regressions with forward selection were performed, to detect the items explaining the best variance of the reading scores. After a Principal Component Analysis of the Conner's, the associations of the 4 retained factors (hyperactivity, social relations, attention/concentration, and sensitivity) with reading scores were examined using Spearman's rho and regressions with forward selection. In addition the impact of Internalizing and Externalizing scores on reading skills, after control of the Conner's "attention" factor, were examined. Given the number of subjects $(n=201)$ correlations were significant at $\mathrm{p}<0.05$ if $>$ abs $(0.16)$; they were considered as strong if $>$ abs $(0.40)$, moderate if $>$ abs $(0.30)$, and low otherwise.

Statistical analyses were performed using SPSS software package version 20 .

\section{Results}

201 children performed the reading tasks. Their ages were between 84-96 months $(\mathrm{M}=89.4, \mathrm{SD}=3.2)$. The teacher-rated TRF and Conner's were completed for $87 \%(n=175)$ of the children. Reading scores were not significantly different according to the presence/absence of missing data for TRF.

\section{Reading task}

Reading time varied from 42 to $414 \mathrm{sec}$, with a mean of $99.0 \mathrm{sec}$. $(\mathrm{SD}=47.8)$. Regarding accuracy, the number of errors was from 0 to 54 with a mean of $9.7(\mathrm{SD}=8.8)$. The Comprehension score was from 0 to 23 with a mean of $16.2(\mathrm{SD}=4.8)$. A strong correlation was found between reading time and reading accuracy $(r=.60, n=201, p<.001)$ and a lower, yet significant, correlation between comprehension and the other two factors, reading time $(\mathrm{r}=-.24, \mathrm{n}=201, \mathrm{p}<.001)$ and accuracy $(\mathrm{r}=-.30, \mathrm{n}=201, \mathrm{p}<.001)$. Girls performed better on reading time $(\mathrm{t}=2.03, \mathrm{df}=199, \mathrm{p}=.04)$ and reading accuracy $(\mathrm{t}=2.37, \mathrm{df}=199, \mathrm{p}=.02)$.

\section{Conners-28 questionnaire and reading skills}

Table 1 shows the Spearman correlation coefficients of each item with reading time, reading errors and comprehension. These coefficients are expected to be positive for reading time (more reading time in the case of positive answers) and for reading errors (more errors in the case of positive answers), but negative for comprehension (lower comprehension in the case of positive answers). "Difficulty in learning" was the item which was most strongly correlated with the reading scores, followed by "distractibility or attention span problem", "fails to finish things that he starts" and "childish and immature". All the other items were either not related or only partially and weakly related to the three reading scores. In some cases (e.g., "demands must be met immediately), the sign of the correlation coefficients was opposite to the one expected. 
Citation: Lazaratou H, Vlassopoulos M, Kalogerakis Z, Zelios G (2014) Inattention, Passivity and Reading Ability in Attention-Deficit Hyperactivity Disorder in a Greek Community Sample. J Psychol Abnorm Child 3: 109. doi:10.4172/2329-9525.1000109

\begin{tabular}{|c|c|c|c|}
\hline & $\begin{array}{c}\text { Reading } \\
\text { Time }\end{array}$ & $\begin{array}{c}\text { Reading } \\
\text { errors }\end{array}$ & $\begin{array}{l}\text { Compre- } \\
\text { hension }\end{array}$ \\
\hline 1. Restless in the « squirmy » sense & 11 & 14 & -.01 \\
\hline 2. Makes inappropriate noises when he shouldn't & .04 & .11 & .02 \\
\hline 3. Demands must be met immediately & -.13 & -.04 & .05 \\
\hline 4. Acts « smart » (impudent or sassy) & -.04 & 01 & .02 \\
\hline 5. Temper outbursts and unpredictable behaviour & .15 & .07 & .03 \\
\hline 6. Overly sensitive to criticism & -.03 & .02 & -.10 \\
\hline 7. Distractibility or attention span a problem & $.30^{\star \star *}$ & $.36^{\star * *}$ & $-.17^{*}$ \\
\hline 8. Disturbs other children & .06 & .09 & .05 \\
\hline 9. Daydreams & .03 & .06 & -.06 \\
\hline 10. Pouts and sulks & 10 & 11 & $-.17^{*}$ \\
\hline 11. Mood changes quickly and drastically & .08 & .05 & -.03 \\
\hline 12. Quarrelsome & .14 & 15 & -.04 \\
\hline 13. Submissive attitude toward authority & -.03 & 11 & -.14 \\
\hline 14. Restless, always up and on the go & .09 & .07 & .05 \\
\hline 15. Excitable, impulsive & .07 & $.18^{\star}$ & -.04 \\
\hline 16. Excessive demands for teacher's attention & -.06 & -.02 & .09 \\
\hline 17. Appears to be unaccepted by the group & $.18^{*}$ & $.23^{\star *}$ & -.15 \\
\hline 18. Appears to be easily led by other children & $.16^{*}$ & $.20^{\star *}$ & -.08 \\
\hline 19. No sense of fair play & .09 & $.16^{*}$ & -.04 \\
\hline 20. Appears to lack leadership & .001 & .11 & -.06 \\
\hline 21. Fails to finish things that he starts & $.31^{* \star *}$ & $.37^{\star \star *}$ & $-.19^{* *}$ \\
\hline 22. Childish and immature & $.22^{* *}$ & $.34^{* * *}$ & $-.16^{*}$ \\
\hline 23. Denies mistakes or blames others & .10 & .15 & -.08 \\
\hline 24. Does not get along well with other children & .11 & .11 & $-.16^{*}$ \\
\hline 25. Uncooperative with classmates & .09 & .09 & $-.20^{* *}$ \\
\hline 26. Easily frustrated in efforts & .14 & $.18^{*}$ & $-.26^{* \star *}$ \\
\hline 27. Uncooperative with teacher & .13 & .11 & $-.20^{* *}$ \\
\hline 28. Difficulty in learning & $.47^{\star \star *}$ & $.52^{\star \star \star}$ & $-.30^{* \star *}$ \\
\hline
\end{tabular}

Note. ${ }^{*} \mathrm{p}<.05 ;{ }^{* *} \mathrm{p}<.01 ;{ }^{* * *} \mathrm{p}<.001$.

Table 1: Spearman correlation coefficients of the Conner's items with reading scores.

Table 2 shows the results of regression models with a forward selection of the items, and $p<.05$ for an item to enter. For each reading score two forward selections were performed, with and without the "difficulty in learning" item, which was always the first selected. Selected items had either a positive or a negative coefficient. "Distractibility or attention span problem" and "uncooperative with teacher" were associated with slower reading; however, "demands must be met immediately" was associated with faster reading. For reading errors, "distractibility or attention span problem", "fails to finish things that he starts" and "submissive attitude towards authority" were related to more errors; but "demands must be met immediately" "daydreams" and "easily frustrated in efforts" were related to less errors. Excessive demands for teacher's attention was linked to better comprehension; and "fails to finish things that he starts" and "easily frustrated in efforts" were associated with poorer comprehension. Note, however, that Conner's items explain only a small percentage of the variance of reading comprehension (15\% with the "difficulty in learning item" and $11 \%$ without this item).

Table 3 shows the results of Principal Component Analyses of the 28 questions of the questionnaire. Items 6 ("Overly sensitive to criticism"), 13 ("Submissive attitude toward authority"), 20 ("Appears to lack leadership"), and 28 ("Difficulty in learning") were poorly related to the total score (Table 4), (F1 unrotated). The four factor structure was chosen as the most appropriate solution and accounted for $64 \%$ of the variance. In the four factor solution, items were retained if their loading on the factor was $>.50$ after varimax rotation.
New variables were then generated, one for each factor, summing up the teacher's answers (i.e. 0, 1, 2, or 3 for "never", "rarely", "sometimes", and "very often" respectively) to the corresponding items. The names of these four new variables were chosen in accordance with the questions they were based on: hyperactivity (10 items), sociability (6 items), inattention (4 items), and "sensitivity" (6 items). Boys presented higher levels of Hyperactivity $(\mathrm{p}<.001)$ and Total problems $(\mathrm{p}=.01)$ than girls.

As Table 4 shows in relation to the 4 factors of the Conner's questionnaire, only the third, attention/concentration, was significantly related to the scores evaluating reading. Forward selection of the Conner's factors by regression models, with $\mathrm{p}<.05$ for a factor to enter, showed that attention/concentration problems were always associated with lower reading scores, but hyperactivity was associated with faster reading and better comprehension (when attention/concentration was partialled out) (Table 5).

\begin{tabular}{|l|c|c|c|c|}
\hline \multicolumn{4}{|c|}{ Reading Time } \\
\hline
\end{tabular}

\begin{tabular}{|l|c|c|c|c|}
\hline Regression with item 28 & & & & 0.35 \\
\hline 7. Distractibility or attention span a problem & 2.9 & 0.8 & $<.001$ & \\
\hline 10.Pouts and sulks & -2.7 & 0.9 & .003 & \\
\hline 13.Submissive attitude towards authority & 1.4 & 0.6 & .03 & \\
\hline 27. Uncooperative with teacher & -2.8 & 1.4 & .04 & \\
\hline 28. Difficulty in learning & 5.1 & 0.8 & $<.001$ & \\
\hline Regression without item 28 & & & & 0.30 \\
\hline 3. Demands must be met immediately & -2.1 & 1.0 & .03 & \\
\hline 7. Distractibility or attention span a problem & 4.2 & 0.9 & $<.001$ & \\
\hline 9. Daydreams & -1.8 & 0.9 & .04 & \\
\hline 13.Submissive attitude towards authority & 1.8 & 0.7 & .007 & \\
\hline 21.Fails to finish thinks that he starts & 4.0 & 1.0 & $<.001$ & \\
\hline 26.Easily frustrated in efforts & -2.6 & 1.1 & .02 & \\
\hline \multicolumn{1}{|c|}{ Reading Comprehension } & & & & 0.15 \\
\hline Regression with item 28 & -1.1 & 0.5 & .03 & \\
\hline 16.Excessive demands for teacher's attention & 1.8 & 0.6 & .003 & \\
\hline 24.Does not get along well with other children & -1.6 & 0.7 & .04 & \\
\hline 28.Difficulty in learning & -1.6 & 0.4 & $<.001$ & \\
\hline Regression without item 28 & & & \\
\hline 16. Excessive demands for teacher's attention & 1.7 & 0.5 & .001 & \\
\hline 21.Fails to finish thinks that he starts & & & \\
\hline 26. Easily frustrated in efforts & & & \\
\hline
\end{tabular}

a Proportion of variance explained.

Table 2: Regressions of the reading scores on forward selected items of the Conner's questionnaire. 
Citation: Lazaratou H, Vlassopoulos M, Kalogerakis Z, Zelios G (2014) Inattention, Passivity and Reading Ability in Attention-Deficit Hyperactivity Disorder in a Greek Community Sample. J Psychol Abnorm Child 3: 109. doi:10.4172/2329-9525.1000109

Page 4 of 7

Item

1. Restless in the « squirmy " sense

2. Makes inappropriate noises when he shouldn't

3. Demands must be met immediately

4. Acts « smart » (impudent or sassy)

5. Temper outbursts and unpredictable behavior

6. Overly sensitive to criticism

7. Distractibility or attention span a problem

8. Disturbs other children

9. Daydreams

10. Pouts and sulks

11. Mood changes quickly and drastically

12. Quarrelsome

13. Submissive attitude toward authority

14. Restless, always up and on the go

15. Excitable, impulsive

16. Excessive demands for teacher's attention

17. Appears to be unaccepted by the group

18. Appears to be easily led by other children

19. No sense of fair play

20. Appears to lack leadership

21. Fails to finish things that he starts

22. Childish and immature

23. Denies mistakes or blames others

24. Does not get along well with other children

25. Uncooperative with classmates

26. Easily frustrated in efforts

27. Uncooperative with teacher

28. Difficulty in learning

${ }^{*} \mathrm{~F} 1$ : first factor before rotation

** The four factors after varimax rotation are: F1: hyperactivity; F2: sociability; F3: attention/concentration; F4: Sensitivity

Table 3: Principal-Components Structure for the Conner's Teacher Rating Scale.

\begin{tabular}{|c|c|c|c|}
\hline & \multicolumn{3}{|c|}{ Reading } \\
\hline & Time & $\mathrm{Nb}$ of errors & Comprehension \\
\hline \multicolumn{4}{|l|}{ Conners Factors } \\
\hline Hyperactivity & .10 & .12 & .06 \\
\hline Social Problems & .21 & .12 & -.12 \\
\hline Attention/concentration & $.41^{*}$ & $.44^{*}$ & $-.26^{\star}$ \\
\hline Sensitivity & .14 & .08 & -.12 \\
\hline Total & .23 & .20 & -.07 \\
\hline
\end{tabular}

Note. ${ }^{*} \mathrm{p}<.05$

Table 4: Spearman correlations coefficients of the Conner's factors with reading scores.

\begin{tabular}{|c|c|c|c|c|}
\hline & $\mathbf{b}^{*}$ & $\mathbf{s d}^{* *}$ & $\mathbf{p}$ & $\mathbf{R} 2^{*+*+}$ \\
\hline Reading Time & & & & 0.19 \\
\hline Hyperactivity & -1.76 & 0.72 & .02 & \\
\hline Attention/concentration & 7.99 & 1.27 & $<.001$ & \\
\hline Reading Errors & & & & 0.24 \\
\hline Attention/concentration & 1.77 & 0.25 & $<.001$ & \\
\hline Sensitivity & -0.51 & 0.24 & .04 & \\
\hline Reading Comprehension & & & & 0.13 \\
\hline Hyperactivity & 0.26 & 0.07 & $<.001$ & \\
\hline Attention/concentration & -0.65 & 0.13 & $<.001$ & \\
\hline
\end{tabular}

* estimator;

** standard deviation of the estimator

*** proportion of variance explained

Table 5: Regressions of the reading scores on forward selected Conner's factors. 


\section{TRF}

Overall, correlations of the TRF externalizing or internalizing scales and reading scores were low $(\mathrm{r} \leq .25)$. As expected, the Conner's scale was strongly correlated with teachers' TRF (e.g., $r=.81$ between Conner's hyperactivity and externalising problems; $r=.77$ between Conner's sensitivity and internalizing problems).

TRF externalizing or internalizing scales did not have a significant impact on reading scores after partialling out Conner's attention/ concentration, with one exception: TRF's externalizing problems were associated with less reading errors $(\mathrm{p}=.002)$, when the attention/ concentration effect was controlled.

\section{Discussion}

The results of this study show that reading ability is better in girls than in boys, which is in accordance with the existing literature. In four different epidemiological studies reviewed by Rutter et al. [45], reading difficulties were more prevalent in boys than in girls.

Furthermore, our results show that boys were more hyperactive according to the teachers. In ADHD, the question of gender is a controversial issue. Where clinical settings are concerned, male predominance is evident. Boys with ADHD are more likely to exhibit externalizing behaviours, in particular rule-breaking, than girls are [46]. Girls with ADHD are less impaired than boys in most parameters. Their behaviour is less disruptive and they have fewer learning difficulties related to reading or mathematics $[47,48]$.

The most important finding in this study is related to the relationship between "inattention" and "reading difficulties" in children who exhibit ADHD. It has already been shown that ADHD symptoms and reading significantly predict each other. Moreover it appears that ADHD symptoms are a significantly stronger predictor of reading than the other way around. Furthermore, the two conditions, ADHD and reading difficulties, are highly heritable and their association is possibly attributed to shared genetic factors [13,49]. It must be noted however that inattentiveness plays a more direct causal role in reading difficulties as the child grows older, as the cognitive demands of reading become more apparent [50].

In this study, the factor structure of the Conner's Questionnaire is similar to previous analyses [27-29,51] with a four factor structure as the most appropriate solution. As expected from previous studies, only one of the four released factors (i.e. Attention/Concentration) was correlated with reading abilities. "Difficulty in learning" has consistently been found to be one of the four items composing the "attention/ concentration" factor: when teachers report attention difficulties in a pupil, they usually also note "learning difficulties" in the same pupil. This finding has been reported in Greece [42], in France [35] and elsewhere $[29,51]$. These same studies, as well as longitudinal investigations from Australia and New Zealand [32], show that hyperactivity alone is not related to academic and learning difficulties. Moreover, in many studies the stronger phenotypic and genetic association of reading with inattentive rather than with hyperactive-impulsive ADHD symptoms is stressed [13,36-38]. Nevertheless, a longitudinal twin study on the association between ADHD symptoms and reading [52] showed that inattentive and hyperactive - impulsive symptoms of ADHD both contributed to the prediction of reading, but inattentiveness was a significantly stronger predictor.

In our study we stress the key role of the "learning difficulties" item in the "inattention" factor of the Conner's: firstly, it suggests that reported inattention is a marker of learning difficulties rather than a marker for specific attention problems, which could be objectively assessed by specific attention tests; secondly, it explains the "comorbidity" of ADHD with "learning difficulties", when an ADHD diagnosis relies greatly upon the Conner's. In other words, the "inattention" factor is a "learning difficulties" factor.

In the present study, the presence of some "externalizing problems", including hyperactivity, in children showing learning difficulties according to the teacher had a positive rather than a negative impact on reading skills. A possible interpretation of this unexpected finding is that when a child shows learning difficulties according to the teacher, passive behaviour (i.e. zero or close to zero in "externalizing problems") has a negative impact on his/her learning, as it exhibits lack of motivation, whereas on the contrary, the presence of some "externalising problems" may have a positive impact on learning. In a multivariate analysis of the Conner's Teacher Rating Scale with low-income preschool children, three factors were retained; conduct problems, hyperactivity, and passivity. "Difficulty in learning" loaded on the "passivity" factor [53]. Our findings are also in accordance with a study that examined the behaviours related to academic engagement exhibited by students with ADHD [54]. It indicates that classroom activities that require passive engagement, such as listening to lectures or silently reading a passage are particularly problematic for students with ADHD and have a negative effect on their school functioning.

\section{Study Limitations}

A limitation of the study is that the sample is not representative. It includes children from public schools from only one suburb of Athens which correspond to a middle socioeconomic status. Children from lower and upper socioeconomic classes are excluded from the study. Another limitation is related to the transversal nature of the study. Longitudinal studies are needed to examine the persistence or, on the contrary, the transitory character of the observed or reported difficulties in schoolchildren.

\section{Conclusions}

Among the three subtypes of ADHD according to DSM-IV, the predominantly inattentive has more possibilities of presenting reading difficulties, even more so if it is combined with a child's passivity. The implications of this finding are that in screening for learning difficulties, the factor of a child's passivity must be addressed. It appears that children benefit when their engagement in learning tasks and procedures is more active, and that this may particularly have a positive impact on children with inattention and potential learning difficulties.

\section{References}

1. Makris N, Biederman J, Monuteaux MC, Seidman LJ (2009) Towards conceptualizing a neural systems-based anatomy of attention-deficit/ hyperactivity disorder. Dev Neurosci 31: 36-49.

2. Nikolas MA, Burt SA (2010) Genetic and environmental influences on ADHD symptom dimensions of inattention and hyperactivity: a meta-analysis. J Abnorm Psychol 119: 1-17.

3. Steinhausen $\mathrm{HC}$ (2009) The heterogeneity of causes and courses of attentiondeficit/hyperactivity disorder. Acta Psychiatr Scand 120: 392-399.

4. Ficks CA, Waldman ID (2009) Gene-environment interactions in attentiondeficit/hyperactivity disorder. Curr Psychiatry Rep 11: 387-392.

5. Millichap JG (2008) Etiologic classification of attention-deficit/hyperactivity disorder. Pediatrics 121: e358-365.

6. Loe IM, Feldman HM (2007) Academic and educational outcomes of children with ADHD. Ambul Pediatr 7: 82-90.

7. Semrud-Clikeman M, Biederman J, Sprich-Buckminster S, Lehman BK Faraone SV, et al. (1992) Comorbidity between ADDH and learning disability: 
Citation: Lazaratou H, Vlassopoulos M, Kalogerakis Z, Zelios G (2014) Inattention, Passivity and Reading Ability in Attention-Deficit Hyperactivity Disorder in a Greek Community Sample. J Psychol Abnorm Child 3: 109. doi:10.4172/2329-9525.1000109

a review and report in a clinically referred sample. J Am Acad Child Adolesc Psychiatry 31: 439-448.

8. Willcutt EG, Pennington BF, Boada R, Ogline JS, Tunick RA, et al. (2001) A comparison of the cognitive deficits in reading disability and attention-deficit/ hyperactivity disorder. J Abnorm Psychol 110: 157-172.

9. Gayan J, Willcutt E, Fisher S, Francs C, Cardon L, et al. (2005) Bivariate linkage scan for reading disability and attention-deficit/ hyperactivity disorder localizes pleiotropic loci. Journal of Child Psychology and Psychiatry 46: 1045-1056.

10. Willcutt EG, Pennington BF, Smith SD, Cardon LR, Gayán J, et al. (2002) Quantitative trait locus for reading disability on chromosome $6 p$ is pleiotropic for attention-deficit/hyperactivity disorder. Am J Med Genet 114: 260-268.

11. Del'Homme M, Kim TS, Loo SK, Yang MH, Smalley SL (2007) Familial association and frequency of learning disabilities in ADHD sibling pair families. J Abnorm Child Psychol 35: 55-62.

12. Zumberge A, Baker LA, Manis FR (2007) Focus on words: a twin study of reading and inattention. Behav Genet 37: 284-293.

13. Willcutt EG, Pennington BF, Olson RK, DeFries JC (2007) Understanding comorbidity: a twin study of reading disability and attention-deficit/hyperactivity disorder. Am J Med Genet B Neuropsychiatr Genet 144B: 709-714.

14. Rowe KJ, Rowe KS (1992) The relationship between inattentiveness in the classroom and reading achievement (Part B): an explanatory study. J Am Acad Child Adolesc Psychiatry 31: 357-368.

15. Roy P, Rutter M (2006) Institutional care: associations between inattention and early reading performance. J Child Psychol Psychiatry 47: 480-487.

16. Cohen NJ, Vallance DD, Barwick M, Im N, Menna R, et al. (2000) The interface between $\mathrm{ADHD}$ and language impairment: an examination of language, achievement, and cognitive processing. J Child Psychol Psychiatry 41: 353362.

17. Shanahan MA, Pennington BF, Yerys BE, Scott A, Boada R, et al. (2006) Processing speed deficits in attention deficit/hyperactivity disorder and reading disability. J Abnorm Child Psychol 34: 585-602.

18. Cain K, Oakhill J, Bryant P (2000) Phonological skills and comprehension failure: A test of phonological processing deficit hypothesis. Reading and Writing: An Interdisciplinary Journal 13: 31-56.

19. Toplak ME, Rucklidge JJ, Hetherington R, John SC, Tannock R (2003) Time perception deficits in attention-deficit/ hyperactivity disorder and comorbid reading difficulties in child and adolescent samples. J Child Psychol Psychiatry 44: 888-903.

20. Breier JI, Fletcher JM, Foorman BR, Klaas P, Gray LC (2003) Auditory temporal processing in children with specific reading disability with and without attention deficit/hyperactivity disorder. Journal of Speech Language and Hearing Research 46: 31-42.

21. St Sauver JL, Katusic SK, Barbaresi WJ, Colligan RC, Jacobsen SJ (2001) Boy/girl differences in risk for reading disability: potential clues? Am J Epidemio 154: 787-794.

22. Ohan JL, Visser TA (2009) Why is there a gender gap in children presenting for attention deficit/hyperactivity disorder services? J Clin Child Adolesc Psychol 38: $650-660$

23. Hawke JL, Olson RK, Willcut EG, Wadsworth SJ, DeFries JC (2009) Gender ratios for reading difficulties. Dyslexia 15: 239-242.

24. Shaywitz BA, Shaywitz SE, Pugh KR, Constable RT, Skudlarski P, et al. (1995) Sex differences in the functional organization of the brain for language. Nature 373: 607-609.

25. Biederman J, Kwon A, Aleardi M, Chouinard VA, Marino T, et al. (2005) Absence of gender effects on attention deficit hyperactivity disorder: findings in nonreferred subjects. Am J Psychiatry 162: 1083-1089.

26. Rucklidge JJ, Tannock R (2002) Neuropsychological profiles of adolescents with ADHD: effects of reading difficulties and gender. J Child Psychol Psychiatry 43: 988-1003.

27. Conners CK (1969) A teacher rating scale for use in drug studies with children Am J Psychiatry 126: 884-888.

28. Conners CK (1973) Rating scales for use in drug studies with children Psychopharmacology Bulletin Special Issue (Pharmacotherapy of Children):24-29
29. Goyette CH, Conners CK, Ulrich RF (1978) Normative data on revised Conners Parent and Teacher Rating Scales. J Abnorm Child Psychol 6: 221-236.

30. Achenbach TM (1991a) Manual for the Child Behavior Checklist/4-18 and 1991 Profile. Burlington: University of Vermont, Department of Psychiatry.

31. Achenbach TM (1991b) Manual for the Teacher's Report Form and 1991 Profile. Burlington: University of Vermont, Department of Psychiatry.

32. McGee R, Prior M, Willams S, Smart D, Sanson A (2002) The long-term significance of teacher-rated hyperactivity and reading ability in childhood: findings from two longitudinal studies. J Child Psychol Psychiatry 43: 10041017.

33. Weiss M, Worling D, Wasdell M (2003) A chart review study of the inattentive and combined types of ADHD. J Atten Disord 7: 1-9.

34. Dellatolas G, Watier L, Giannopulu I, Chevrie-Muller C (2007) [Behavior difficulties, attention difficulties and learning problems in children aged from 3.5 to 8 years: a longitudinal school study]. Arch Pediatr 14: 227-233.

35. Giannopulu I, Escolano S, Cusin F, Citeau H, Dellatolas G (2008) Teachers' reporting of behavioural problems and cognitive-academic performances in children aged 5-7 years. Br J Educ Psychol 78: 127-147.

36. Pham AV (2013) Differentiating Behavioral Ratings of Inattention, Impulsivity, and Hyperactivity in Children: Effects on Reading Achievement. J Atten Disord.

37. Costa HC, Perdry H, Soria C, Pulgar S, Cusin F, et al. (2013) Emergent literacy skills, behavior problems and familial antecedents of reading difficulties: a follow-up study of reading achievement from kindergarten to fifth grade. Res Dev Disabil 34: 1018-1035.

38. Sims DM, Lonigan CJ (2013) Inattention, hyperactivity, and emergent literacy: different facets of inattention relate uniquely to preschoolers' reading-related skills. J Clin Child Adolesc Psychol 42: 208-219.

39. Greven CU, Rijsdijk FV, Asherson P, Plomin R (2012) A longitudinal twin study on the association between ADHD symptoms and reading. J Child Psychol Psychiatry 53: 234-242.

40. Dittman CK (2013) The Impact of Early Classroom Inattention on Phonologica Processing and Word-Reading Development. J Atten Disord

41. Roussos A, Karantanos G, Richardson C, Hartman C, Karajiannis D, et al. (1999) Achenbach's Child Behavior Checklist and Teachers' Report Form in a normative sample of Greek children 6-12 years old. Eur Child Adolesc Psychiatry 8: 165-172.

42. Roussos A, Richardson C, Politikou K, Marketos S, Kyprianos S, et al. (1999) The Conners-28 teacher questionnaire in clinical and nonclinical samples of Greek children 6-12 years old. Eur Child Adolesc Psychiatry 8: 260-267.

43. Vamvoukas $M$ (1991) The assessment of text readability in the school textbook â€œMy Languageâ€. Gloss 27: 4-28 (in Greek).

44. Zelios G (2005) Development and standardization of an assessment tool for reading ability in children aged 7 to 8 years. Postgraduate Thesis. University of loannina, School of Medicine, Library of Postgraduate Studies in Social and Child Psychiatry (in Greek)

45. Rutter M, Caspi A, Fergusson D, Horwood LJ, Goodman R, et al. (2004) Sex differences in developmental reading disability: new findings from 4 epidemiological studies. JAMA 291: 2007-2012.

46. Abikoff HB, Jensen PS, Arnold LL, Hoza B, Hechtman L, et al. (2002) Observed classroom behavior of children with ADHD: relationship to gender and comorbidity. J Abnorm Child Psychol 30: 349-359.

47. Newcorn JH, Halperin JM, Jensen PS, Abikoff HB, Arnold LE, et al. (2001) Symptom profiles in children with ADHD: effects of comorbidity and gender. $J$ Am Acad Child Adolesc Psychiatry 40: 137-146.

48. Biederman J, Mick E, Faraone SV, Braaten E, Doyle A, et al. (2002) Influence of gender on attention deficit hyperactivity disorder in children referred to a psychiatric clinic. Am J Psychiatry 159: 36-42.

49. Paloyelis Y, Rijsdijk F, Wood AC, Asherson P, Kuntsi J (2010) The genetic association between ADHD symptoms and reading difficulties: the role of inattentiveness and IQ. J Abnorm Child Psychol 38: 1083-1095.

50. Ebejer JL, Coventry WL, Byrne B, Willcutt EG, Olson RK, et al. (2010) Genetic and Environmental Influences on Inattention, Hyperactivity-Impulsivity, and Reading: Kindergarten to Grade 2. Sci Stud Read 14: 293-316.

51. Werry JS, Sprague RL, Cohen MN (1975) Conners' Teacher Rating Scale for 
Citation: Lazaratou H, Vlassopoulos M, Kalogerakis Z, Zelios G (2014) Inattention, Passivity and Reading Ability in Attention-Deficit Hyperactivity Disorder in a Greek Community Sample. J Psychol Abnorm Child 3: 109. doi:10.4172/2329-9525.1000109

use in drug studies with children--an empirical study. J Abnorm Child Psychol 3: $217-229$.

52. Greven CU, Harlaar N, Dale P, Plomin R (2011) Genetic overlap between attention-deficit hyperactivity disorder and reading is largely driven by inattentiveness rather than by hyperactivity-impulsivity. Journal of the Canadian Academy of Child and Adolescent Psychiatry 20: 6-14.
53. Fantuzzo J, Grim S, Mordell M, McDermott P, Miller L, et al. (2001)A multivariate analysis of the revised Conners' Teacher Rating Scale with low-income, urban preschool children. J Abnorm Child Psychol 29: 141-152.

54. Vile Junod RE, DuPaul GJ, Jitendra AK, Volpe RJ, Cleary KS (2006) Classroom observations of students with and without ADHD: Differences across types of engagement. Journal of School Psychology 44: 87-104. 